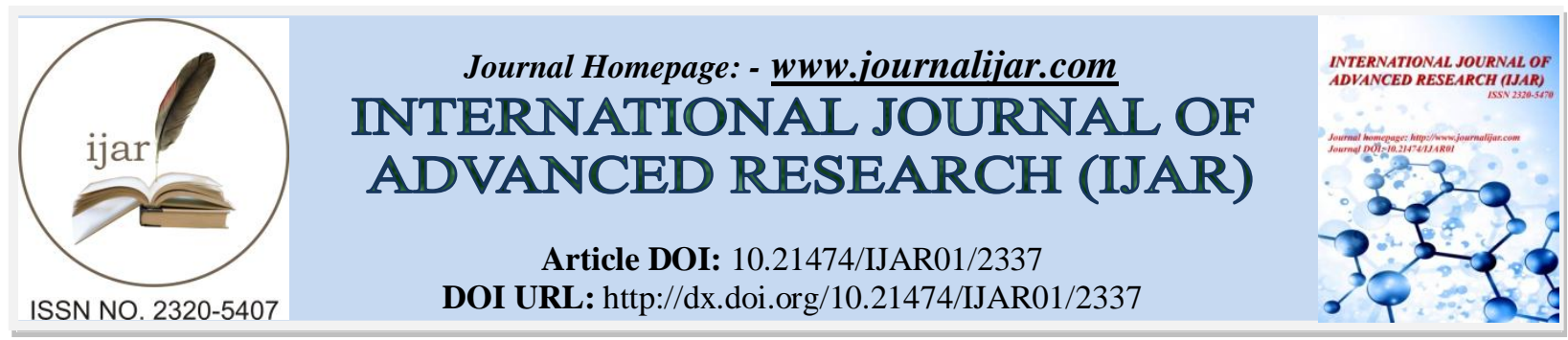

RESEARCH ARTICLE

\title{
UNIVERSITY STRATEGY AND DIGITAL TRANSFORMATION IN HIGHER EDUCATION INSTITUTIONS. A DOCUMENTARY ANALYSIS.
}

Fernando Almaraz-Menendez Ph.D ${ }^{1}$, Alexander Maz-Machado Ph.D ${ }^{2}$ and Carmen Lopez-Esteban Ph.D ${ }^{1}$. 1. Universidad de Salamanca, SPAIN.

2. Universidad de Cordoba, SPAIN.

\section{Manuscript Info}

Manuscript History

Received: 30 September 2016

Final Accepted: 30 October 2016

Published: November 2016

Key words:-

Digitalization, Higher Education, Digital

Transformation, Universities, Teaching

Innovation

\section{Abstract}

Over the past few years Higher Education has felt the influence of different technological and social trends towards digitalization which have led to many teaching innovation projects based on digital technologies. These innovations, far from being isolated and static phenomena, ought to be seen as instances of a genuine digital transformation process of Higher Education. Yet it hasn't just been Higher Education; many other sectors such as the press, banking, television or the music industry have also been affected by digital transformation processes which in many cases have been disruptive. The main argument of this article is that a study of e-innovation in University teaching should be approached within a complete analysis of the digital transformation taking place at Higher Education Institutions, which are highly complex organizations. It is only through adopting this organizational perspective that one can gain a complete vision and overview of the changes and challenges universities are facing. These days digital transformation is a strategic priority for many business organizations. Is this also the case for universities? In order to try and answer this question the article will take a qualitative approach based on documentary analysis. It will look at the results from the analysis of the case of a Spanish university and shows evidence supporting the argument that universities have a conception of digital technologies that is not strategic enough, merely as tools.

Copy Right, IJAR, 2016,. All rights reserved.

\section{Introduction. University and Digitalization:-}

Over the past few years and within the context of adapting to the European Higher Education Area (EHEA), many teaching innovation projects have been developed at Spanish universities, based on digital technologies. We are talking about praiseworthy efforts by members of the teaching faculty which, on many occasions, have been rewarded by universities through acknowledgement in teaching quality evaluation programs. Given that they are "projects", these initiatives are in most cases exploratory in nature, experiences that take place one time but that don't essentially change the previous situation. It would appear to support the idea that the use of digital technologies is a complement that decorates higher education without changing it in its fundamental essence. However, should we take a step back and then observe the situation it can be argued that the impact digitalization is 
having on Higher Education, or could have in the short term, is more significant and could even become disruptive. Many sectors of human activity have seen how the world around them has changed so very quickly because of digitalization. Banking, the media, telecommunications companies, the music industry, tourism (and others/to name a few) have had to reinvent themselves so as to survive. In Higher Education the changes aren't all that small either.

Firstly, traditional face-to-face teaching has become "blended" which means it is a mix of traditional teaching with technological elements. All Spanish universities have virtual campuses which support face-to-face teaching. The technology behind these virtual campuses, that's to say LMS - Learning Management Systems, is the technological tool that has had the highest adoption rate in Higher Education. According to Brown (2015), 99\% of the universities in the USA have some kind of LMS, $85 \%$ of professors use it (56\% on a daily basis) and $74 \%$ of them consider it to be a useful tool to help improve teaching. Whilst it is true that the way they are utilized can be improved and explored in more detail, the fact of the matter is that they are very much a part of the everyday life of university education.

What's more, many traditional universities have incorporated online courses into their academic offering, at At both undergraduate and post-graduate level. The global e-learning market continues to grow: in 2011 the sector was worth some 35.6 billion dollars worldwide (Santamans, 2014; Docebo, 2014). In 2013, 56.2 billion and by the end of 2015 it reached over 107 billion dollars (McCue, 2016). Universities only have a little share of this market. What's even more relevant is the statistic that half of all university students are taking at least one online course at the same time as they are studying for their degree (Pappas, 2014). E-learning is gaining ground on traditional university teaching for various reasons, as it is more cost-efficient but also by virtue that it could become more effective in terms of the knowledge that can be acquired throughout the learning process. At least this is what some studies are claiming which state that information retention can be increased by up to 60\% (Pappas, 2014).

Technological improvements to increase the bandwidth of internet connections are also changing the standard of teaching materials to be included in higher education online courses. The possibility to view videos from both fixed devices as well as mobile phones means that the video format is now essential to ensure teaching quality? (Seatonet al., 2014).

Similarly, other emerging digital technologies such as 3D printing are also already being utilized in university teaching. As an example, 3D models have been used to manipulate and study replicates of fragile objects such as antiques or fossils. Or to quickly produce prototypes of new developments or to resemble the disposition of organs of the body and so to go through a surgical protocol before the operation (Johnsonet al., 2014).

Students themselves have also changed. Now they are a generational group who are very much influenced by the process of digitalization taking place in society. Today's university students were born halfway through the 90 s and thus belong to the so-called millennials (Howe and Strauss, 2003). They grew up with the Internet and interact naturally on social networks, especially using mobile devices (smartphones, tablets and laptops), devices that they also expect to be able to use in their classes at university. They use technology intensively and expect certain technological standards at university that are similar to other aspects of their lives; they feel that technology education is important for their future and careers (Telefónica Global Millennial Survey, 2014).

Apart from undergraduate degree students who are studying in Higher Education for the first time, there is another important group of users for universities - those we seek permanent education (so-called lifelong learning, in other words, studying throughout life). They form a broad group and digital technologies enable them to learn at any given moment and wherever they want, which is of fundamental importance for working professionals who have family obligations whose most precious good is time. What they need is for the university education they require to have these technological facilities. They aren't digital natives but in their everyday lives they are accustomed to using multiple digital services (for instance online banking or online shopping) and will simply expect the institution providing them with post-graduate education to have the same service standards.

The panorama is changing so quickly that it wouldn't be unreasonable to expect a more all-encompassing response by Higher Education Institutions, that is to say, a strategic change. The term digital transformation tends to be used when talking about business organizations and referring to this process of change (Albanese and Manning, 2016; Rogers, 2016). Whilst it isn't our intention to liken academic institutions to business institutions, one cannot deny that the former are very complex organizations as well, offering multiple and different services. We believe that a 
university's strategy should also address how to react to changes brought about by digitalization, given that it isn't just teaching activity that is being affected. There are changes to internal processes that ought to be more agile so as to comply with both expectations by students as well as the university's professionals themselves (academic and administrative). The people who work for many universities tend to be proud of their century-old tradition but hope that management systems are more up-to-date than the age of the institution. On the contrary, they expect for these to be based on the latest technologies and to make their lives easier. New digital technologies are also having a direct impact on a university's technological infrastructure. For instance, the trend towards cloud-computing is transforming the fixed costs that investing in servers would entail into variable costs for hiring cloud services and infrastructure. As a result, one of the most emblematic spaces for IT services at universities, the Data Processing Centre where IT servers are stored could potentially become empty in just a matter of years. This could lead to big changes to the professional profiles and daily activities of those people in charge of managing IT infrastructures. As if this weren't enough, the Internet of Things will also soon bring about the need to digitalize physical infrastructures (Maciá-Pérezet al., 2016).

Many Higher Education institutions own many university buildings that are costly to maintain. The application of digital technologies to turn them into smart buildings, capable of controlling energy consumption would help bring down operational costs. Likewise, as is already happening with smart cities, applying digital technologies could help to improve mobility around campus but would require the implementation of sensor systems and the development of appropriate IT applications. Even more noticeable is that Institutional Communication is changing as well; many universities are creating more digital contact points with their current and potential students as part of an (overall) (greater) multichannel strategy encompassing social networks, mobile applications as well as websites.

In short, our argument is that the impact of digitalization on teaching ought to be regarded as an important part of an overall digital transformation process for Higher Education Institutions, but there are many others that should be considered. We believe that universities are aware of digitalization but lack the tools required to define and tackle the necessary strategic change. We are not the only ones to think this way. The Declaration by Universia Río 2014, which brings together the main conclusions and proposals based on a gathering of more than 1000 Ibero-American chancellors, establishes the ninth strategic key to be the full utilization of digital technologies. It states word-forword that "universities that have still not developed, as profoundly as required, a digital vision that covers its entire potential" (Universia, 2014, p.8).

\section{Methodology Digital Transformation for Higher Education Institutions:-}

Solís, Li and Szymanski (2014) argue that digital transformation is quickly becoming a top priority for many organizations. The study conducted by Brown and Sikes (2012) shows that executives are keen to better understand and take advantage of the new digital environment. In turn, Wang (2014) highlights that one of the key characteristics of this change process is that it are getting speeding up.

Fenwick and Gill (2014) stress that no sector is immune from the change brought about by digitalization and that in many cases this can be disruptive meaning that it can significantly change the sector or even cause it to disappear. For Mehaffy (2012), Higher Education is among those sectors affected.We fully agree with him and feel it is important to analyze how the way in which the impact is being produced and its possible implications. How can we define digital transformation?

Westermannet al. (2014) defines the digital transformation of an organization as being the use of digital technologies to greatly improve its performance and scope. In turn, De la Peña and Cabezas $(2015$, p.52) consider it to be "a necessary process of significant technological and cultural change that the whole organization needs to carry out in order to "live up to" its digital clients".

Our starting point is a rather more general definition of Digital Transformation in Higher Education Institutions as the process of technological and organizational change taking place in these institutions brought about by the development of digital technologies. Duparc (2013) argues that real digital transformation is only achieved when the whole organization understands and embraces the importance of a digital culture (and makes it their own) across all levels. It's not just a technology issue, but rather about people and organizational structures. 
In a recent article, the authors propose a theoretical reference framework for the systematic study of the characteristics of digital transformation in Higher Education Institutions (Almarazet al., 2016). The theoretical model classifies the implications of the digital transformation process into seven dimensions or analysis levels. It doesn't try to take on a technological focus nor does it set out to categorize the technologies used in universities. It is about coming up with an analysis framework focused on studying the influence that emerging digital technologies are having or could have in the immediate future on universities as organizations. Additionally, the model considers the governance of the digital transformation process itself as being the eighth dimension.

For each of the dimensions, variables are defined that specify the analysis level. As such, the result is a theoretical model consisting of eight dimensions andeighteen variables - these are shown in Table 1.

Table 1:- Table summarizing the Analysis Levels and Variables.

\begin{tabular}{|c|c|}
\hline Analysislevel & Variables \\
\hline \multirow[t]{2}{*}{ 01.- TheUniversityCampus } & $01.01 \quad$ Mobilityaroundcampus \\
\hline & Sustainability of the university campus \\
\hline \multirow[t]{2}{*}{ 02.- ITInfrastructure } & Infrastructureforinformationprocessing \\
\hline & Communicationsinfrastructure \\
\hline \multirow[t]{3}{*}{ 03.- Administration } & Automatization of university management processes \\
\hline & Digitalization of the user experience \\
\hline & Impact on interactions with the environment \\
\hline \multirow[t]{3}{*}{ 04.- Teaching } & $04.01 \quad$ Face-to-faceteaching \\
\hline & $04.02 \quad$ Online teaching \\
\hline & Teaching innovation \\
\hline \multirow[t]{2}{*}{ 05.- Research and knowledge transfer } & $05.01 \quad$ Digital resourcesforresearch \\
\hline & 05.02 Digital networks to knowledge transfer \\
\hline \multirow[t]{3}{*}{ 06.- Marketing } & 06.01. $\quad$ Recruiting new students \\
\hline & 06.02. Staying in touch with former students \\
\hline & 06.03. Acquiringadditionalfunds \\
\hline \multirow[t]{2}{*}{ 07.- Communication } & 07.01. Externalcommunciation \\
\hline & 07.02. Internalcommunciation \\
\hline 08.- Governance of digital transformation & 08.01. Responsibility for digital transformation \\
\hline
\end{tabular}

A detailed description of the dimensions and variables can be found in the aforementioned article.

This theoretical reference framework allows us to systematically study the different characteristics of the digital transformation process in Higher Education Institutions. The levels defined should by no means be considered as watertight compartments; there are various links and crossovers between the different dimensions seeing as how certain traits associated with digital transformation for universities affect one or more of the defined levels. As an example, one possible generalizedapplication of teaching innovation based on digital technologies is video tutorials and this is directly linked to changes in the university's IT infrastructure. Likewise, alternative ways to approach teaching such as flipped classroom, would also benefit from changes to the spaces in and around campus, originally designed for lectures.

Data AnalysisandResults.Digital transformation as a strategic priority. A case study:-

One might think for universities it is important to consider digital translation as being a key element in their overall strategy. Doing so would make it possible to align all the efforts madein the area of digital technologies with institutional objectives. Including digital transformation as one of a Higher Education Institution's strategic prioritieswould help it to identify and spot opportunities and risks that they may not be aware of from other perspectives. Thus the question we can pose ourselves here is: Is digital transformation up there among the main priorities of Higher Education Institutions? In other words, are the dimensions related to the digital transformation process as set out in our model part of the University's strategy? Do they figure in its strategic plans?

\section{Research Design:-}

In order to answer this question, it is possible to devisedifferent research designs. We decided on empirical research using case study as the methodological focus. Thanks to Stoecker (1991), we understand case study to be not just a technique of gathering data, but rather a complete research strategy. In other words, it isn't an isolated characteristic 
of the designing research design. It's a complete research methodology that includes everything: the design logic, the methods of collecting information and the data analysis techniques. We chose a medium-sized public Spanish university for the case study. It is a generalist university that offers bachelor degrees (68), master degrees (65), own titles (71) and doctorates (38) across all subjects and disciplines. In total there are 27 Teaching Centres: 16 Faculties, 3 Superior Technical Schools, 7 University Schools and 1 Doctorate School. Research activity is carried out across 63 University Departments and 13 Research Institutes. As an organization, the university studied is made up of a total of 4,363 people, of which 2,257 are Teaching and Research Staff (PDI in Spanish) and 1,106 make up the Administration and Services Staff (PAS in Spanish).

For data collection we followed a documentary research strategy focusing on what we have calledthe Strategic Planning Documentsof the university in question. The results showed here belong to a broader study for which other research questions were considered - therefore two more sets of documents were analyzed but these are not relevant for this article: Execution Documents and ResultSummary Documents. The whole set forms a set of documents whose preparation and filing were not guided by the objectives of the research project (as it could be an interview or a group discussion) but rather is the result of habitual and routineoperations of the entity studied. This has two key advantages: objectivity and detailObjectivity because the documents selected reflect what is really being done, without the researcher's vision getting in the way and detail, due to the large amount of information the documents provide.

\section{The documents studied are all public in nature:-}

1. The University's General Strategic Plan was developed and approved in 2012 and outlines the university's strategy. It is a generaldocument comingfrom the team governing the university but to a certain extent, agreed on by the whole of the university community. Three strategic plans partially derived from the General Strategic Plan and approved in 2014 are also considered: The Virtual Teaching Plan, TheCommunication Plan and TheResearch Plan.

2. The document submitted by the university studied in order to receive the International Campus Excellence seal. The International Campus Excellent Programmefromthe Ministry of Education, Culture and Sports falls within the framework of The Spanish State's University Strategy 2015 whose objective is to modernize Spanish universities. This programme'ssubsequent cycles have called on universities to think up strategic development projects and create socially integrated university environments, with high-quality services that are also sustainable and healthy. The Campus Excellence projects put forward by the universities taking part are topnotch and strategic,and therefore their analysis is very much appropriate. The university studied submitted an excellent project that consisted of 10 programs and 27 subprograms and that was worthy of receiving the Seal of Excellence.

3. The opening speeches given by the Rector of the University at the start of each academic year for the period studied. These are a lot more informal documents in comparison but nonetheless very interesting. Every year, the opening speech marking the start of another academic year contain the priorities for the Chancellor for the year in question, in other words the key messages for what work has to be done. An opportunity to convey to the student body what the Rector considers to be the most important or decisive points at that given moment in time. It is consequently relevant to analyze if any of the digital transformation dimensions feature in these.

We are fully aware that these kinds of organizational documents themselves don't always represent "the truth". We agree with Atkinson and Coffey (2004) that these documents are "social facts" and that they are produced and shared in a social context within the organization. Whilst it is important to bear this in mind at all times, it is nonetheless true thatthey do allow us to objectively get closer to the reality we are trying to study.

For the documentary analysis, the approach proposed by Friese (2014) called "Computer-assisted NCT Analysis" served as a guide. The acronym NCT stands for the English verbs to notice, to collect and to think. These refer to the three basic components of the approach: to observe or notice interesting things in the documents, to collect and code these findings and lastly, to think about and reflect on them, looking for the results of the analysis.

In NCT analysis, the first element consists of identifying and spotting interesting things in the documents, highlighting text segments and assigning them preliminary codes. In our case we started off with an initial set of codes and marked the text segments where they appeared. The codes are keywords associated with the 18 variables set out in our theoretical model. To a certain extent they are similar to the initial coding that Saldaña (2013) called Hypothesis Coding. This type of coding is based on a pre-determined list of codes generated by the researcher with 
the aim of testing certain hypothesis. In our case we didn't seek out to verify and prove a hypothesis per-se, but we did try to identify all the instances in the documentation referring to the variables and dimensions in our theoretical model. In other words, we were checking if the documents contained plans or actions linked to the different dimensions of digital transformation, which essentially equates to an initial check of the hypothesis implied, if digital transformation is present in the Strategic Planning documents of the university studied.

\section{As for the operational aspect, the process followed the steps defined by Silverman (2013):-}

1. Specify the set of codes, keywords and descriptions linked to the variables in the theoretical model. In total, 126.

2. Systematically apply the set of codes to the document set.

3. Calculate the appearance frequency distribution of the code, carried out at three levels: by code or keyword, by variable and by analysis level or dimension. This way there is also a quantitative backing to the analysis, which is recommended by Weber (1990) and Bernard (2011); these two went on to inspire Saldaña (2013) to propose this type of coding in order to verify the hypothesis.

This first coding takes place at the same time as text segments are marked where the keywords appear. These segments are the focus object of the study in the second phase of the NCT analysis.

The "collect" element of NCT analysis refers to the gathering of interesting elements as well as sorting and structuring them. This is a second coding phase in which the segments found are classified and newly coded, looking out for elements in common or connections between the model's variables. Based on the numeric results from the first coding, certain keywords may be ruled out, joined together, broken down or connected. This phase requires a thorough reading of the highlighted text segments as well as the need to contextualize the basic results obtained from the previous stage.

Lastly, the "think" phase involves attempting to extract results from the previous coding processes carried out. These results couldbe in the form of discovering patterns, families, sequences, new typologies and so forth. In this phase the functionalities of interrelation and software visualization take on great importance as they can help us with the documentary analysis - no surprise as to why Friese's method is called Computer-assisted NCT Analysis.

The IT tool that helped us during the process was ATLAS.ti (v.7) which belongs to the CAQDAS software family. CAQDAS stands forComputer-Aided Qualitative Data Analysis Software. ATLAS.ti was developed at the Technical University of Berlin within the framework of the ATLAS project (1989-1992). It was designed to support the analysis of qualitative data and since 1993 successive commercial versions have been brought out, up to the current version number 7 which is the one we utilized for our research.

Even though it is linear and appears to be simple in its approach, NCT analysis is in actual fact a cyclical process that requires various and back and forth iterations regardingthe identification and coding of the highlighted elements. One could say that NCT Analysis has two layers: descriptive and conceptual. At the descriptive level, we carry out a deep exploration of the documents, identifying the interesting segments and coding them. At the conceptual level, the key is to look at the data from the perspective of our research question, looking for answers, arguments and new conceptualizations. On both layers the functionalities of the ATLAS.ti software are of invaluable help.

\section{Research Designvalidity:-}

We agree with Howe andEisenhart (1993) and Sandín (2003)that the question of construct validity ofa research design ought to be considered from the point of view of the logic of the research methodology itself.As a result, we can establish the most-used validation criteria in the methodology of case studies as the ones for our study: construct validity, external validity and reliability, which is exactly what Yin (2003) had put forward,and lastly, triangulation, as per the formulation by Stake (2010).

1. Construct validity. Hammerley (1992) understands construct validity as referring to "the degree to which a model accurately represents the social phenomenon it refers to". The model proposed includes all the elements mentioned in the literature related to digital transformation in organizations, applying them to the case of universities. Thus, it is an integral model that we believe accurately represents the digital transformation phenomenon in Higher Education Institutions. The key has been to keep the aggregation level which at the same 
time makes it complete and manageable. They haven't been any similar models published which is why we are unable to carry out a comparative analysis. As for the type of documents selected for data collection, we feel that they form a set of documents that comply with the characteristicsof authenticity, credibility and representability that Valles (2001) demands.

2. External validity. External validity refers to if the results obtained in the study could be generalized beyond the case studied. The issue of external validity has traditionally always been the main obstacle for carrying out research projects based on cases given that critics would argue that a unique case doesn't really provide a strong enoughbase upon which to make generalizations. Yet where this criticism falls short is because of its own conception. The critical argument is based on an incorrect analogy of quantitative studies based on surveys. These work off a sample andresults are generalized to the complete universe. However, and as Yin (2003) explains, it is not possible to apply the same reasoning for case studies. When carrying out research on cases,one cannot fall in the trap of trying to find a "representative" case with which to generalize the results. Instead, it is necessary to find a research design for the case that can be replicated for other cases. The logic is the same as the one followed in laboratory experiments. A scientist doesn't set out to conduct a "representative" experiment but rather one that is replicable andallows for ongoing knowledge to be added through successive replications.

Whereas in the case of quantitative research methodologies carried out through surveysthe theory is constructed by means of a statistical generalization of the results obtained from the sample, for qualitative case-based research the theory can be established from an analytical generalization based on the possibility of replication. The original case acts as a first test of the theory. From studying this, conclusions can be made concerning the clarity of the theoretical propositions. Or on the contrary, if there is the need to search for alternative explanations. A single case can contribute substantial knowledge to the theory should its results validate it and its research design allow it to be replicated for other cases.

Following this reasoning, in this case study, the important thing is that the university studied doesn't have characteristics that artificially support the theoretical model. Nor does it have features that could make it difficult to replicate the study for other universities. This is why the research design is suitable for analyzing the chosen casein detail and for contrasting the theoretical model for the first time. In the same way, our research design has external validity in the sense that it is perfectly possible to replicate it at other universities.

3. Reliability. The reliability criterion refers to those mechanisms that have featured in the research design in order to make sure that other researchers can follow the same procedures as the original research and so once again carry out the complete analysis of the case study. On the one hand, the data collection procedure and documentary analysis were clearly defined, adhering to a data analysis technique that is well-documented and well-known, Friese's NCT Analysis (2014) we explained earlier. With this we are able to guarantee a thorough analysis of the whole of the documentary set in a structured way and with well-defined phases. On the other hand, the decision to use the ATLAS.ti software also makes it easier for other researchers to repeat the whole analysis of the case. This software brings together the whole of the project in a single place, known as the Hermeneutics Unit (HU), which stores all the Primary Documents (PD), the codes, the marked text segments (quotes) and all the comments (memos) added every step of the way throughout the process.

4. Triangulation. Creswell (2007) argues that triangulation is one of the most utilized validity criteria when it comes to case methodology. Stake (2010) describes various possible triangulation strategies: data-based, theorybased and researchers-based. In our research design we made the decision to include triangulation carried out by three different researchers, the authors of this article, as the validation element. 


\section{Results:-}

The overallfrequency distribution ofkeywords as classified by analysis level (dimensions) are shown in the table below:

Table 2:- Frequency Distribution of Keywords by Dimensions.

\begin{tabular}{|c|c|c|c|c|}
\hline Analysis level & $\begin{array}{l}\text { Execution } \\
\text { Docs. }\end{array}$ & $\begin{array}{c}\text { Result Summary } \\
\text { Docs. }\end{array}$ & $\begin{array}{c}\text { Strategic } \\
\text { Planning } \\
\text { Docs. }\end{array}$ & TOTALS: \\
\hline 01.- The University Campus & 38 & 10 & 6 & 54 \\
\hline 02.- IT Infrastructure & 106 & 74 & 8 & 188 \\
\hline 03.- Administration & 233 & 88 & 10 & 331 \\
\hline 04.- Teaching & 247 & 286 & 52 & 585 \\
\hline 05.- Research and knowledge transfer & 91 & 117 & 20 & 228 \\
\hline 06.- Marketing & 44 & 36 & 21 & 101 \\
\hline 07.- Communication & 139 & 202 & 10 & 351 \\
\hline 08.- Governance of digital transformation & 1 & 0 & 0 & 1 \\
\hline TOTALS: & 899 & 813 & 127 & 1839 \\
\hline
\end{tabular}

The same frequency distribution ofkeywords, but now classified by variables are shown in the table below:

Table 3:- Frequency Distribution of Keywords by Variables.

\begin{tabular}{|l|r|r|r|r|}
\hline \multicolumn{1}{|c|}{ Variables } & \multicolumn{1}{c|}{$\begin{array}{c}\text { Execution } \\
\text { Docs. }\end{array}$} & $\begin{array}{c}\text { Result } \\
\text { Summary } \\
\text { Docs. }\end{array}$ & $\begin{array}{c}\text { Strategic } \\
\text { Planning Docs. }\end{array}$ & TOTALS: \\
\hline 01.01 Mobility around campus & 20 & 5 & 3 & 28 \\
\hline 01.02 Sustainability of the university campus & 18 & 5 & 3 & 26 \\
\hline 02.01 Infrastructure for information processing & 26 & 15 & 1 & 42 \\
\hline 02.02 Communications infrastructure & 80 & 59 & 7 & 146 \\
\hline $\begin{array}{l}\text { 03.01 Automatization of university management } \\
\text { processes }\end{array}$ & 66 & 15 & 6 & 87 \\
\hline 03.02 Digitalization of the user experience & 157 & 61 & 4 & 222 \\
\hline 03.03 Impact on interactions with the environment & 10 & 12 & 0 & 22 \\
\hline 04.01 Face-to-face teaching & 41 & 47 & 9 & 97 \\
\hline 04.02 Online teaching & 163 & 137 & 38 & 338 \\
\hline 04.03 Teaching innovation & 43 & 102 & 5 & 150 \\
\hline 05.01 Digital resources for research & 80 & 111 & 10 & 201 \\
\hline 05.02 Digital networks to knowledge transfer & 11 & 6 & 10 & 27 \\
\hline 06.01. Recruiting new students & 35 & 27 & 11 & 73 \\
\hline 06.02. Staying in touch with former students & 8 & 8 & 10 & 26 \\
\hline 06.03. Acquiring additional funds & 1 & 1 & 0 & 2 \\
\hline 07.01. External communciation & 94 & 137 & 9 & 240 \\
\hline 07.02. Internal communciation & 45 & 65 & 1 & 111 \\
\hline 08.01. Responsibility for digital transformation & 1 & 0 & 0 & 1 \\
\hline & 899 & 813 & 127 & 1839 \\
\hline
\end{tabular}


The research question we asked ourselves was "are dimensions of the digital transformation process present in the University's strategy?

In order to answer this, we can observe the following graphs which show the appearance frequency of keywords in the Planning Documents both by dimensions and by variables.

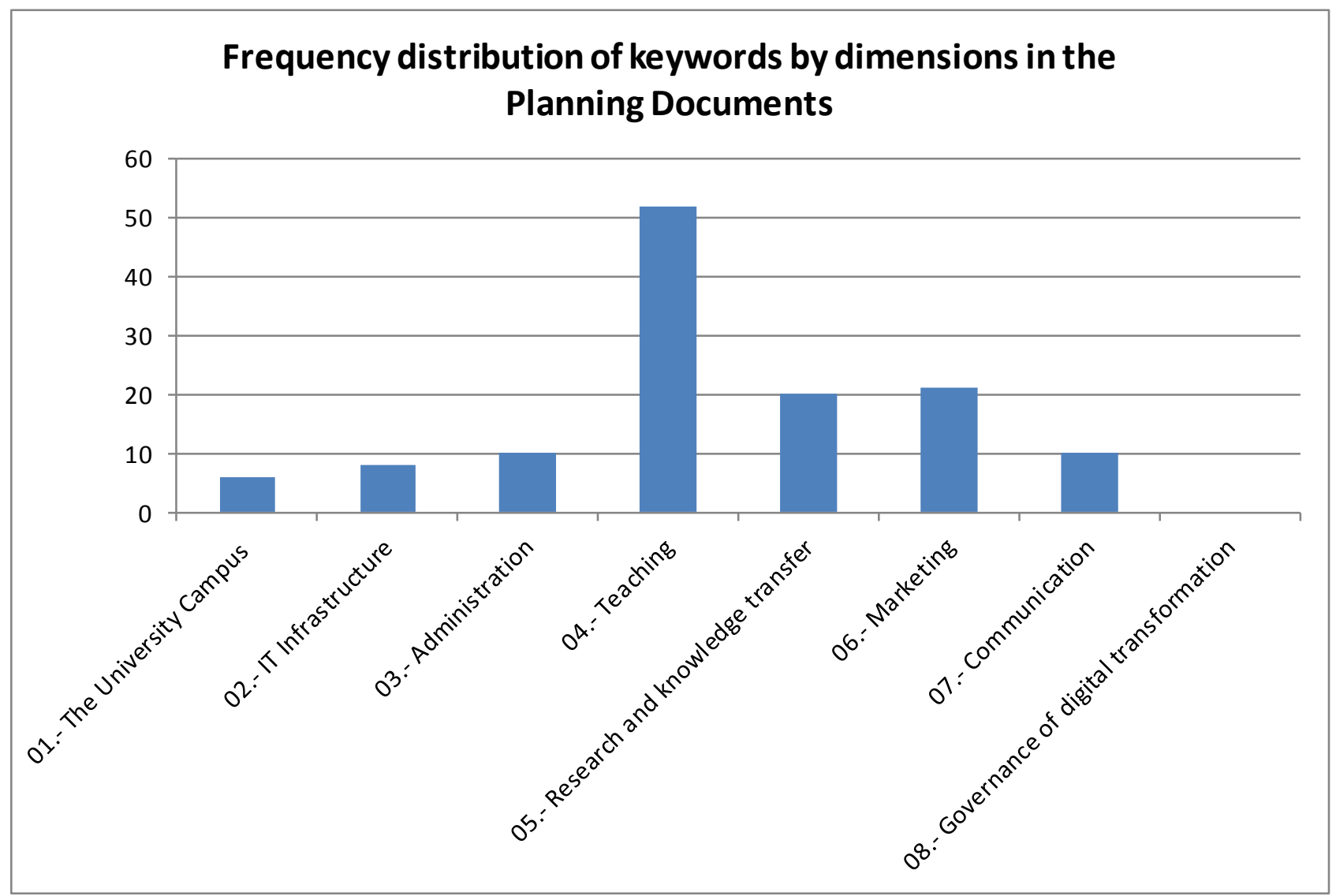

Figure1:- Frequency Distribution of Keywords by Dimensions in the Planning Documents 


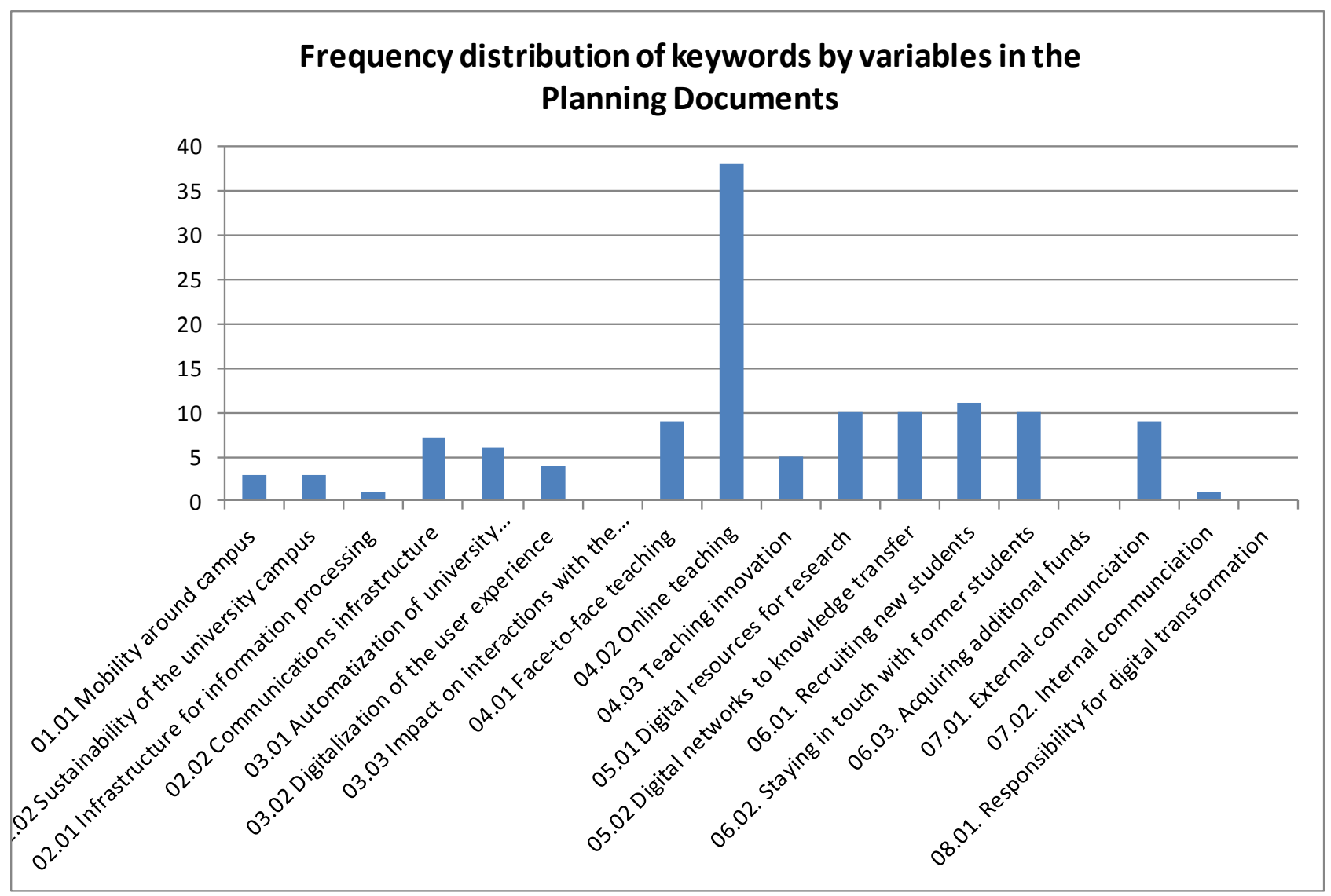

Figure 2:- Frequency Distribution of Keywords by Variables in the Planning Documents.

Both graphs are highly revealing. The dimension that clearly stands out is Teaching and, within that, the variable 04.02 Online Teaching. It is clear that any digital transformation concerns are predominantly focused on changes for the University's teaching activities.In the documents analyzed, we found clear evidence of plans to adaptto the consequences of digital transformation affecting teaching. There is more evidence of this linked to adapting to the new online teaching market whereasthere appears to be less concernfor teaching innovation based on digital technologies (variable 04.03).

\section{Discussion of the findings:-}

It can be observed in the graphs that there is a similar appearance frequency of keywords related to Dimension 5 (Research and Application) and Dimension 6 (Marketing). The former, Research and Application, appears in the university's strategic plans making references to the need to growdigital resources for research purposes (variable 05.01, which contains codes such as e-journals, digital databases, digital storage and so forth) and actions to be takenso as to apply digital technologies to improvingtheknowledgetransference (variable 05.02). As forthe sixth dimension, Marketing, we found references to plans to make use of digital technologies both in terms of attracting new students as well as keeping in contact with former students. Yet nothing concerning the use of digital technologies to raise additional funds for the university (i.e. online donations, crowdfunding and so on).

It is interesting to note that the graphs show less concernfor the impact of digital technologies on Communication (Dimension 07) than Marketing (Dimension 06). The university has a "Communication Plan" (document DOP09) that was put together as an extension of the General Strategic Plan but this does not reveal any particular or special focus on neither online reputation nor the University's digital identity. There are very few references concerning the actual use of digital technologies and are more focused on external communication rather than internal communication. 
Even more surprising is the lack of references in Dimensions 2 (IT Infrastructure) and Dimension 3 (Administration). Plans regarding investment in IT infrastructure appear primarily as references to updating and modernizingcommunication infrastructures (Variable 02.02). However, there is only one reference to any other type of IT infrastructure (Variable 02.01).It can be deduced thatfor Senior Management at the university studied, their concept of IT infrastructures is that it is something merely operational which should be managed by technical experts. It would appear that there is no one really pushing for a more modern way of thinking regarding digital technologies as an element with important strategic components and so it should figure in the institution's strategic planning. The small number of occurrences of the keywords in variable 03.01 (Automatization of university management processes) and 03.02 (Digitalization of the user experience) back up this theory. The university's software infrastructure is not considered to be an essential element in order to get maximum performance out of new digital technologies but is rather more of an administrative issue and therefore it is not present in strategic planning contexts. The documents analyzed show that development in these areas is carried out reactively and not proactively, i.e. more about complying with external obligations rather than own initiative and the desire to seek out a competitive edge compared with other Higher Education Institutions. On the one hand reacting to the legal obligation of developing electronic administration mechanisms and on the other hand reacting to the demands of users. These are users who expect a service level online that is similar to what they know from other aspects of their daily lives (the possibility for students to register online, online services for employees, web portal and so forth).

It is worth highlighting as well that the complete lack of representation ofvariable 03.03suggests thatnew trends towards Open Data or the possibilities of Big Data have not been considered as part of strategic planning.

The finding that without a doubt supports our standpointof aconception of technologybeing merely a tool, is the lack of references related to the administration of digital technologies. In stark contrast to the theoretical importance we gave the role of leadership in digital transformation, there is not a single reference made in any of the planning documents analyzed to assuming responsibility for digital transformation, nor the general governance of technology. There are no plans to create any commission to overlook the investments needed for digital transformation, nor appoint figures similar to that of the Chief Digital Officer, nor talk of any other strategic planning mechanisms related to the governance of digital transformation.

Lastly, we would like to point out that there are references which appear relating to the application of digital technologies in the variables Mobility (01.01) and Sustainability (01.02) within Dimension 1 (The University Campus). The appearance frequency is low which could indicate that the application of digital technologies in this area may be perceived as a possibility in the medium-term but that it isn't a short-term priority.

\section{Conclusions:-}

Generally speaking, from the results obtained it can be concluded that digital transformation, as an overall concept, is not a main preoccupationfor the university studied. This doesn't mean that there isn't an appreciation that they should make the most of the advantages presented by digital technologiesfor the university's main activities. In fact, there is evidence supporting that they are aware of thisneed, across all the dimensions. What is missing though is anappreciation of this phenomenon as a whole and of the implications this can have for managing the university.

The aspect of digital transformation considered to be the most important is the impact of digital technologies on teaching. The difference compared to the other analysis levels is so significant that it leads us to think that this finding could also appear in future replications of this research carried out at other Higher Education Institutions. At the other end of the scale lies the analysis level related to digital transformation of the university campus, with very few references.

The evidence all points to the fact that the understanding the government body of the university studied hasof the role of digital technologiesis not strategic enough. In other words, for them digital technologiesare merely tools without a strategic component.We can deduce this given that the dimensions related to technological infrastructure and electronic administration hardly figure in the documents analyzed. Itbecomes even clearer if we consider the complete lack of actions related to the administration and governance of technologies and digital transformation. Our impression is that this isn't some isolated case and that, generally speaking, universities are not giving digital transformation the importance it deserves. 
We feel that this article's research topic is relevant enough so as to be worthy of the focus and attentionof other research projects in the near future. One area that subsequent research clearly could elaborate and expand on is the aforementioned replication of the analysishere for other case studies: does digital transformation play a greater role in the strategic planning of other universities?

Lastly, it is worth highlighting that the chosen research approach has proven to be highly useful in trying to shed light on the research question. Similar documentary analysis could thus be applied to researchon other topics related to the digital transformation of Higher Education Institutions.

\section{References:-}

1. Albanese, J., and Manning, B. (2016): Revive. How to Transform Traditional Businesses into Digital Leaders. New Jersey: Pearson Education.

2. Almaraz, F., Maz-Machado, A. and López, C. (2016): Análisis de la transformación digital de las Instituciones de Educación Superior. Un marco de referencia teórico. Edmetic, Revista de Educación Mediática y TIC, 5(2). (http://goo.gl/zjojP9) (2016-09-16).

3. Atkinson, P. and Coffey, A. (2004): Analysing documentary realities. In D. Silverman (Ed.), Qualitative research: Theory, Method and Practice. London: Sage Publications,pp. 56-75.

4. Bernard, H. R. (2011): Research Methods in Anthropology: Qualitative and Quantitative Approaches. Rowman Altamira.

5. Brown, M. (2015): Six Trajectories for Digital Technology in Higher Education. EDUCAUSE Review, 50(4): 16-28.(http://goo.gl/0xh1sv) (2016-09-29).

6. Brown, B. and Sikes, J. (2012): Minding your digital business. McKinsey \& Company.

7. Creswell, J. W. (2007): Qualitative inquiry and research design: Choosing among five approaches. ThousandOaks: SagePublications.

8. de la Peña, J., and Cabezas, M. (2015): La gran oportunidad. Claves para liderar la transformación digital en las empresas y en la economía. Barcelona: EdicionesGestión 2000.

9. Docebo (2014): E-Learning Market Trends \& Forecast 2014 - 2016 Report. Napoles, Italia. (http://goo.gl/LJbFAM) (2016-09-16).

10. Duparc, P. F. (2013): Evolution in the c-suite as organisationsmaximise growth opportunities: The Chief Digital Officer takes centre stage.(http://goo.gl/38tkrk) (2016-09-15).

11. Fenwick, N. and Gill, M. (2014): The Future of Business Is Digital: The Powerful Advantages of Embracing Dynamic Ecosystems of Value. Forrester Research, Inc. (http://goo.gl/nqcibS) (2016-09-15).

12. Friese, S. (2014): Qualitative data analysis with ATLAS.ti. Los Angeles: Sage Publications.

13. Hammersley, M. (1992): What's Wrong with Ethnography?: Methodological Explorations. London: Routledge.

14. Howe, K. and Eisenhart, M. (1993): Criterios de investigación cualitativa (y cuantitativa). Prolegómenos. Revista de Educación, 300: 173-189. (http://goo.gl/kwiZ2Z) (2016-09-29).

15. Howe, N. and Strauss, W. (2003): Millennials Go to College: Strategies for a New Generation on Campus. Washington, DC: American Association of Collegiate Registrars and Admissions Officers.

16. Johnson, L., Adams Becker, S., Estrada, V. and Freeman, A. (2014): NMC Horizon Report: 2014 Higher Education Edition. Austin, Texas, EstadosUnidos: The New Media Consortium.(http://goo.gl/Tah2T0) (201609-15).

17. Maciá-Pérez, F., Berná, J. V., Sánchez, J. M., Lorenzo, I., and Fuster, A. (2016): Smart University: Hacia una universidad más abierta. Alicante: Marcombo.

18. McCue, T. J. (2016): Online Learning Industry Poised for $\$ 107$ Billion In 2015. (http://goo.gl/oWXpVM/) (2016-09-15).

19. Mehaffy, G. L. (2012): Challenge and change. Educause Review, 47(5): 25-42.(http://goo.gl/LXGw69) (201609-15).

20. Pappas, C. (2014): Top 10 e-Learning Statistics for 2014 You Need To Know.(http://goo.gl/5eF9qd) (2016-09$15)$.

21. Rogers, D. L. (2016): The Digital Transformation Playbook: Rethink Your Business for the Digital Age. New York, United States: Columbia Business School Publishing.

22. Saldaña, J. (2013): The Coding Manual for Qualitative Researchers. London: SagePublications.

23. Sandín, M. P. (2003): Investigación Cualitativa en Educación. Fundamentos y Tradiciones. Madrid: McGrawHill/Interamericana de España.

24. Santamans, J. M. (2014): El mercado global del e-learning. Barcelona: OBS Online Busines School.

25. Seaton, D. T., Nesterko, S., Mullaney, T., Reich, J. and Ho, A. D. (2014): Characterizing Video Use in the 
Catalogue of MIT xMOOCs. eLearning Papers, 37: 33-41. (http://goo.gl/Pd1zUM) (2016-09-15).

26. Silverman, D. (ed.) (2013): Doing Qualitative Research: A Practical Handbook. London: Sage Publications.

27. Solis, B., Li, C. and Jaimy Szymanski. (2014). The 2014 state of digital transformation. Altimeter Group. (http://goo.gl/SMZuMh) (2016-09-15).

28. Stake, R. (2010): The art of case study research. Thousand Oaks: Sage Publications.

29. Stoecker, R. (1991): Evaluating and rethinking the case study. The Sociological Review, 39(1): 88-112. (http://goo.gl/DMhVpD) (2016-09-15).

30. Telefónica S.A. (2014): Resultados de la encuesta a la generación global del milenio de Telefónica. Los jóvenes de hoy en día son los líderes del mañana. (http://goo.gl/TX5Wmp) (2016-09-15).

31. UNIVERSIA (2014): CARTA UNIVERSIA RIO 2014. Río de Janeiro: III Encuentro Internacional de Rectores Universia. (http://goo.gl/DwSqRO) (2016-09-15).

32. Valles, M. S. (2001): Ventajas y desafíos del uso de programas informáticos (e.g. ATLAS.tiyMAXqda) en el análisis cualitativo. Una reflexión metodológica desde la groundedtheory y el contexto de la investigación social española Actas del Primer Seminario sobre Investigación Avanzada Cualitativa Asistida por ordenador. Granada: Fundación Centro de Estudios Andaluces. (http://goo.gl/JVBdF5) (2016-09-19).

33. Wang, R. (2014): Constellation's 2014 Outlook on Dominating Digital Business Disruption. Constellation Research Inc. (http://goo.gl/s2ppRP) (2016-09-15).

34. Weber, R. P. (1990): Basic content analysis. London: Sage Publications.

35. Westerman, G., Bonnet, D. and McAfee, A. (2014): Leading Digital: Turning Technology into Business Transformation. London: Harvard Business Press.

36. Yin, R. K. (2003): Case study research: design and methods. London: Sage Publications. 